response relationship was found for phase 2, phase 3 and PVM, but not in phase 1 (table 1). Few joints showed enhancement in phase 1 and a clear doseresponse relationship was found for pain during the last 24 hours only (data not shown).

\begin{tabular}{|c|c|c|c|}
\hline \multirow{2}{*}{\multicolumn{4}{|c|}{$\begin{array}{l}\text { Associations between FOI Enhancement } \\
\text { and Pain in the same DIP and PIP Joints. }\end{array}$}} \\
\hline & & & \\
\hline & $\begin{array}{l}\text { Self-reported } \\
\text { pain last } 24 \\
\text { hours }\end{array}$ & $\begin{array}{l}\text { Self-reported } \\
\text { pain last } 6 \\
\text { weeks }\end{array}$ & $\begin{array}{l}\text { Tender joint } \\
\text { on clinical } \\
\text { exam }\end{array}$ \\
\hline & OR $(95 \% \mathrm{CI})$ & OR $(95 \% \mathrm{Cl})$ & OR $(95 \% \mathrm{Cl})$ \\
\hline \multicolumn{4}{|c|}{ FOI phase 1} \\
\hline Grade 0 & 1.00 (ref.) & 1.00 (ref.) & 1.00 (ref.) \\
\hline Grade 1-3 & $\begin{array}{l}1.50(0.94 \\
2.40) \\
\end{array}$ & \begin{tabular}{|l|}
$1.92(1.20$ \\
$3.09)$ \\
\end{tabular} & \begin{tabular}{|l|}
$2.42(1.37$ \\
$4.25)$ \\
\end{tabular} \\
\hline \multicolumn{4}{|c|}{ FOI phase 2} \\
\hline Grade 0 & 1.00 (ref.) & 1.00 (ref.) & 1.00 (ref.) \\
\hline Grade 1 & $\begin{array}{l}1.26 \text { (1.02, } \\
1.55)\end{array}$ & $\begin{array}{l}1.15(0.93, \\
1.44)\end{array}$ & $\begin{array}{l}2.15 \text { (1.81, } \\
2.55)\end{array}$ \\
\hline Grade 2 & $\begin{array}{l}1.94(1.58 \\
2.38)\end{array}$ & $\begin{array}{l}1.92(1.52, \\
2.41)\end{array}$ & $\begin{array}{l}2.69(2.21, \\
3.26)\end{array}$ \\
\hline Grade 3 & $\begin{array}{l}2.25 \text { (1.61, } \\
3.15)\end{array}$ & $\begin{array}{l}2.53(1.73, \\
3.69)\end{array}$ & $\begin{array}{l}4.00(2.85, \\
5.59)\end{array}$ \\
\hline \multicolumn{4}{|c|}{ FOI phase 3} \\
\hline Grade 0 & 1.00 (ref.) & 1.00 (ref.) & 1.00 (ref.) \\
\hline Grade 1 & $\begin{array}{l}1.76(1.42 \\
2.17)\end{array}$ & $\begin{array}{l}1.73(1.40 \\
2.14)\end{array}$ & $\begin{array}{l}2.15(1.77 \\
2.61)\end{array}$ \\
\hline Grade $2+3 *$ & $\begin{array}{l}2.29(1.30 \\
4.06) \\
\end{array}$ & $\begin{array}{l}2.51(1.33 \\
4.73) \\
\end{array}$ & $\begin{array}{l}3.21(1.91 \\
5.39) \\
\end{array}$ \\
\hline \multicolumn{4}{|c|}{ FOI Prima Vista Mode } \\
\hline Grade 0 & 1.00 (ref.) & 1.00 (ref.) & 1.00 (ref.) \\
\hline Grade 1 & $\begin{array}{l}1.36 \text { (1.14, } \\
1.61)\end{array}$ & $\begin{array}{l}1.38 \\
(1.14,1.68)\end{array}$ & $\begin{array}{l}2.20(1.88, \\
2.56)\end{array}$ \\
\hline Grade 2** & \begin{tabular}{|l|}
$2.37(1.88$ \\
$2.98)$ \\
\end{tabular} & \begin{tabular}{|l|}
$2.33(1.81$ \\
$3.00)$ \\
\end{tabular} & $\begin{array}{l}3.22(2.57 \\
4.04) \\
\end{array}$ \\
\hline \multicolumn{4}{|c|}{$\begin{array}{l}\text { * Grades } 2 \text { and } 3 \text { combined due to few joints with } \\
\text { grade } 3 \text { in phase } 3 .{ }^{* *} \text { No joints with grade } 3 \text { in prima } \\
\text { vista mode (PVM). }\end{array}$} \\
\hline
\end{tabular}

Conclusions: In this first hand OA study, FOI enhancement was frequently found in the DIP and PIP joints, whereas the method seems insensitive to detect inflammation in the CMC-1 joints. FOI enhancement was related to self-reported pain and to tender joints on clinical examination, supporting the validity of the FOI examination in patients with hand $O A$.

Disclosure of Interest: None declared

DOI: 10.1136/annrheumdis-2018-eular.4735

\section{FRI0585 PREVALENCE OF ANTI-ACETYLATED PROTEIN ANTIBODIES IN INFLAMMATORY ARTHRITIS, OSTEOARTHRITIS, CONNECTIVE TISSUE DISEASES AND ITS DISCRIMINATIVE CAPACITY AS DIAGNOSTIC MARKER FOR EARLY RHEUMATOID ARTHRITIS}

P. Studenic ${ }^{1}$, H. Bang ${ }^{2}$, A. Alunno ${ }^{3}$, D. Sieghart ${ }^{1}$, D. Aletaha ${ }^{1}$, S. Blüml ${ }^{1}$, H. Haslacher ${ }^{4}$, J.S. Smolen ${ }^{1}$, G. Steiner ${ }^{1}{ }^{1}$ Internal Medicine 3, Division Of Rheumatology, Medical University Vienna, Vienna, Austria; ${ }^{2}$ Orgentec Diagnostika GmbH, Mainz, Germany; ${ }^{3}$ Rheumatology Unit, Department of Medicine, University of Perugia, Perugia, Italy, ${ }^{4}$ Department of Laboratory Medicine, Medical University Vienna, Vienna, Austria

Background: Numerous post-translationally modified proteins have been described as auto-antigens in rheumatoid arthritis (RA) patients. Antibodies (abs) against acetlyated (ac) peptides (AAPA) have recently been reported in RA patients, but not yet been evaluated in other inflammatory and non-inflammatory rheumatologic conditions; therefore their specificity (spec) and sensitivity (sens) remains unclear.

Objectives: To determine the prevalence of AAPA in RA, healthy subjects and other rheumatic diseases in order to evaluate their diagnostic potential for discriminating RA, healthy and other rheumatic diseases.

Methods: We obtained serum samples of patients with early untreated RA, established RA ( $>3$ years), osteoarthrits (OA), systemic lupus erythematosus, granulomatosis with polyangiitis (GPA), polymyositis, axial spondyloarthritis, primary Sjögren's syndrome and healthy subjects. AAPA were measured by ELISA using peptides derived from mutated vimentin (acetylation of lysine or ornithine in position 7 or 2 (inverse peptide), as antigen. Receiver operating characteristics and logistic regression analyses were used to assess the discriminative capacity of AAPA.

Results: Areas under the curves (AUC) were significant in early RA (eRA; $n=120$; $75 \%$ female, mean disease duration: $-0.07+0.51$ years, mean symptom duration $1.49 \pm 2.01$ years) versus healthy subjects for IgG-abs against ac lysine, inverse lysine and ornithine (AUC of $0.666,0.687,0.800$, respectively). We chose a cutoff of $20 \mathrm{U} / \mathrm{ml}$ putting an emphasise on high spec, with balanced sens (ac-lysine: spec: 97.0\%; sens: 32.5\%;+likelihood ratio (LR) 10.7, Cl: 3.4-33.7; ac-inverselysine: spec: $80.7 \%$; sens: 42\%;+LR 2.2, Cl: 1.3-3.6; ac-ornithine: spec: $93.9 \%$; sens: $39.2 \% ;+$ LR $6.5 ; \mathrm{Cl}: 2.9-14.5)$. Analyses of positivity for multiple ab-reactivity revealed increasing + LR by number of abs, with $100 \%$ specifity when all 3 AAPAs are detected (table 1). Testing this cutoff against OA patients showed similar specificities, but with lower +LR (2 AAPA:+LR 3.48, Cl: 1.9-6.6). Sens is increased when testing established RA versus healthy controls, with ac-ornithine performing best (ac-lysine: 49.2\%, Cl: 42.0-56.5; ac-inv-lysine: 35.2\%, Cl: 28.5-42.4; acornithin: $53.9 \%, \mathrm{Cl}: 46.6-61.0)$

We found that practically only RA patients showed three different AAPA reactivities (in eRA: $39 \%$ positive for ac-ornithine abs, 33\% for ac-lysine abs, $48 \%$ for inverse ac-lysine abs). Polymyositis and GPA patients showed the lowest prevalence of AAPA (Graph 1A).

Among eRA patients $17 \%$ were found to be exclusively positive for AAPA, while $39 \%$ were also positive for rheumatoid factor (RF) and anti-citrullinated antibodies (ACPA) (distribution in Graph 1B). Also in RF- and ACPA- patients the presence of one AAPA identified RA patients vs. healthy subjects with a spec of $77.7 \%$ and those with 2 AAPA reactivities with even $97 \%$ respectively.

Abstract FRI0585 - Table 1. Sensitivity, specificity, positive and negative likelihood ratio (LR) for identifying early RA patients against healthy controls by the number of AAPA reactivities

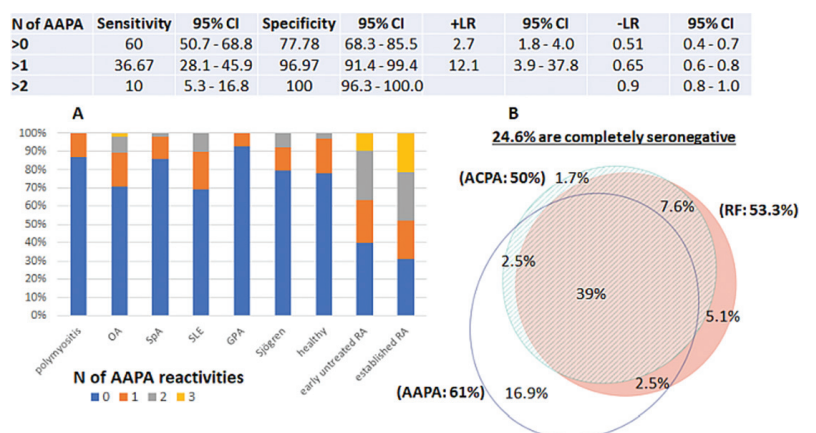

Graph 1A: Prevalence (in\%) of IgG antibodies against the 3 different acetylated peptides using $20 \mathrm{U} / \mathrm{ml}$ as cutoff

Graph 1B: Venn diagram, outlining the distribution and overlap of AAPA (blue circle), ACPA (striped circle) and RF (rose circle) in early rheumatoid arthritis patients $(n=120)$

Conclusions: AAPA are highly prevalent autoantibodies in early RA, closing a further gap of seronegativity, with only $24.6 \%$ of early RA patients remaining negative for RF, ACPA or AAPA. In particular, multiple reactivity to AAPA increased the specificity for eRA, also adding diagnostic value beyond RF and ACPA.

Disclosure of Interest: P. Studenic: None declared, H. Bang Employee of: Orgentc Diagnostika $\mathrm{GmbH}$, A. Alunno: None declared, D. Sieghart: None declared, D. Aletaha: None declared, S. Blüml: None declared, H. Haslacher: None declared, J. Smolen: None declared, G. Steiner: None declared DOI: 10.1136/annrheumdis-2018-eular.3945 


FRI0586

LONGITUDINAL ASSESSMENT OF CORTICAL INTERRUPTIONS AND VBMD IN RA AND HEALTHY SUBJECTS USING HR-PQCT

M. Peters ${ }^{1}$, J. van den Bergh ${ }^{2}$, P. Geusens ${ }^{3}$, A. Scharmga ${ }^{1}$, D. Loeffen ${ }^{4}$ R. Weijers ${ }^{4}$, B. van Rietbergen ${ }^{5}$, A. van Tubergen ${ }^{1} .{ }^{1}$ Rheumatology, MUMC; ${ }^{2}$ Rheumatology, MaastrichtUMC and UHasselt, Maastricht, Netherlands; ${ }^{3}$ Rheumatology, MaastrichtUMC and UHasselt, genk, Belgium; ${ }^{4}$ Radiology, MUMC, Maastricht, ${ }^{5}$ Faculty of Biomedical Engeneering, TU Eindhoven, Eindhoven, Netherlands

Background: Preservation, repair and progression of cortical interruptions in finger joints has been observed in RA using conventional radiography, MRI, ultrasound and high-resolution peripheral quantitative computed tomography (HRpQCT). Accurate and quantitative information about such changes over time, however, is still lacking.

Objectives: To evaluate changes over one year in cortical interruptions (number, surface area and volume), bone density (vBMD) and micro-structural parameters from HR-pQCT scans of finger joints in RA and healthy subjects (HS) using a recently developed semi-automatic algorithm for cortical interruptions detection. ${ }^{1}$ Methods: Baseline and 1 year follow up HR-pQCT scans of finger joints of 32 patients with RA ( 221 joints, $53 \%$ on biologic DMARDSs (bDMARDs)) and $32 \mathrm{HS}$ (117 joints) were analysed for changes in cortical interruption, density and morphological parameters. Mean changes (at the group level) and proportions of joints (at the joint level) with changes beyond least significant changes were calculated after correction for baseline damage.

Results: At baseline, 530 interruptions (3.25/joint) were identified in RA, and 136 (1.45/joint) in HS. The mean of the interruption parameters did not change in either group, except for a significant increase in number of interruptions in PIP joints in RA. However, the proportion of joints showing repair in interruption volume was higher in RA than in $\mathrm{HS}(6.6 \%$ versus $1.7 \%, \mathrm{p}=0.041)$. Changes in cortical interruption parameters were negatively correlated with changes in cortical BMD and thickness $(p<0.01)$. Mean vBMD decreased more and more joints showed loss of vBMD in RA than in $\mathrm{HS}\left(-4.4\right.$ versus $-1.1 \mathrm{mgHA} / \mathrm{cm}^{3}$ and $26.7 \%$ versus $12.9 \%$, respectively, both $p<0.01)$. Proportionally more joints showed interruptions and loss of vBMD in patients with synthetic DMARDs (sDMARDS) compared to bDMARDs $(6.1 \%$ versus $1.8 \%$ and $31.3 \%$ versus $17.2 \%$, respectively, both $\mathrm{p}<0.05)$.

Conclusions: Using HR-pQCT based semi-automatic cortical interruption analysis a large number of interruptions was identified in RA and HS. Cortical interruptions, vBMD and micro-structural parameters were more impaired in RA, of which VBMD and micro-structural parameters further deteriorated. Patients on sDMARDs had more joints with progression in number of interruptions and more loss of vBMD compared to bDMARDs.

\section{REFERENCE:}

[1] Peters M, Scharmga A, de Jong J, van Tubergen A, Geusens P, Arts JJ, Loeffen D, Weijers R, van Rietbergen B, van den Bergh J. An automated algorithm for the detection of cortical interruptions on high resolution peripheral quantitative computed tomography images of finger joints. PLoS One 2017 Apr 20;12(4):e0175829.

Disclosure of Interest: None declared

DOI: 10.1136/annrheumdis-2018-eular.6382

\section{FRI0587 LOW BACK PAIN DUE TO ENTHESOPATHY OF ERECTOR SPINE MUSCLE: A COMPARATIVE US AND MRI STUDY IN PATIENTS WITH ILIAC CREST PAIN SYNDROME}

P.T. Todorov ${ }^{1}$, M. Kalcheva ${ }^{2}$, A. Marinkov ${ }^{3}$, A. Batalov ${ }^{4} .{ }^{1}$ Rheumatology, Medical University, Kaspela University Hospital, Plovdiv, ${ }^{2}$ Radiology, Specialized imaging Laboratory 'Rusev", Sofia; ${ }^{3}$ Rheumatology, Kaspela University Hospital; ${ }^{4}$ Rheumatology and internal Diseases, Medical University Plovdiv, Kaspela University Hospital, Plovdiv, Bulgaria

Background: lliac crest pain syndrome (ICPS) is a regional pain syndrome, that is particularly common in patients with low back pain (LBP). It is characterised clinically by pain perceived maximally at the most medial part of the posterior iliac crest, and patients' recognition of the pain provoked by a systematic digital palpation in this area, as "their" typical one. Though ICPS is very frequently encountered in LBP, the exact etiology of this syndrome was not established. Based on anatomical data, it was suggested that ICPS could be caused by a tendopathy/ enthesopathy of erector spine (ES) muscle attachments to the medial iliac crest (MIC)(. ${ }^{1}$ In a previous anatomical and ultrasound (US) study we showed that this in fact might be the case.

Objectives: The purpose of this study was, regarding the existing clinical diagnostic criteria for the ICPS as a "gold standard", to establish the sensitivity, specificity, positive and negative predictive values (PPV and NPV) and the overall accuracy of the US and the Magnetic Resonance Imaging (MRI) assessment of the entheses of the ES muscle at the MIC in patients with LBP and features indicative of ICPS.

Methods: 25 patients ( 9 men, 16 women, mean age 43.12 \pm 11.83 . mean BMI $25.07 \pm 2.36$ ) with anamnesis of chronic "nonspecific" (after lateral X-ray and standard clinical examination) LBP perceived maximally in the region of the MIC uni- or bilaterally were included. First a systematic palpation of the posterior MIC bilaterally was performed to diagnose ICPS clinically. Then in two successive days each patient underwent MRI examination of the lower back (lumbar and sacroiliac regions), with an enlarged field of view in the sagittal plane, and a standardised US examination of the ES terminal tendons and entheses bilaterally. The MRI were assessed by a radiologist with 10 years of experience in MRI. The sonographies were performed by a rheumatologist with 7 years of experience in US and analysed in regards with the OMERACT definition of enthesopathy. As a single US lesion at any enthesis is a common finding, the presence of at least two pathological features were required to classify given entheses as abnormal.

Results: : ICPS was identified clinically in 20 of the patients ( 15 unilateral and 5 bilateral), thus 25 of the total 50 entheses were clinically pathological. Comparing to the clinical findings, the calculated sensitivity, specificity, PPV, NPV and overall accuracy of the US and the MRI assessments of the ES enthesis at the MIC are placed in table 1:

\begin{tabular}{cccccc}
\hline & $\begin{array}{c}\text { Sensitivity } \\
(95 \% \mathrm{Cl})\end{array}$ & $\begin{array}{c}\text { Specificity } \\
(95 \% \mathrm{Cl})\end{array}$ & $\begin{array}{c}\text { PPV } \\
(95 \% \mathrm{Cl})\end{array}$ & $\begin{array}{c}\mathrm{NPV} \\
(95 \% \mathrm{Cl})\end{array}$ & $\begin{array}{c}\text { Accuracy } \\
(95 \% \mathrm{Cl})\end{array}$ \\
\hline US & $88 \%(69 \%-97 \%)$ & $80 \%(60 \%-$ & $82 \%(67 \%-$ & $87 \%(69 \%-$ & $84 \%(71 \%-$ \\
& & $93 \%)$ & $91 \%)$ & $93 \%)$ & $93 \%)$ \\
MRI & $64 \%(43 \%-82 \%)$ & $80 \%(59 \%-$ & $76 \%(58 \%-$ & $70 \%(56 \%-$ & $71 \%(59 \%-$ \\
& & $93 \%)$ & $88 \%)$ & $80 \%)$ & $85 \%)$ \\
\hline
\end{tabular}

Conclusions: This study shows that enthesopathy of the ES muscles could be the unrecognised cause for most of the cases of ICPS -a regional syndrome particularly common in LBP. US performed better than the MRI in diagnosing this pathological condition, that may reflect the fact that radiologists are not used to assess these structures. The good diagnostic properties of US in ICPS could be of value when assessing patients with otherwise "nonspecific" LBP.

\section{REFERENCE:}

[1] Bogduk N. Clinical anatomy of the lumbar spine and sacrum. Elsevier 2005.

Disclosure of Interest: None declared

DOI: 10.1136/annrheumdis-2018-eular.6607

\section{FRI0588 ULTRASOUND COULD HAVE PREVENTED DMARD ESCALATION IN RHEUMATOID ARTHRITIS WITH FIBROMYALGIA}

R. Chakr ${ }^{1}$, J.C.O. Santos ${ }^{1}$, L.D.S. Alves ${ }^{1}$, N. P. B. D. Andrade ${ }^{1}$, A. Ranzolin ${ }^{2}$, C.

V. Brenol ${ }^{1} .{ }^{1}$ Universidade Federal do Rio Grande do Sul, Porto Alegre;

${ }^{2}$ Universidade Federal de Pernambuco, Recife, Brazil

Background: Despite the growing body of evidence, the proper use of ultrasound (US) in monitoring disease activity still needs better understanding. ${ }^{1,2}$ As an objective measure, US could prevent overtreatment in situations of overestimation of clinical disease activity, such as fibromyalgia, present in up to $20 \%$ of patients with rheumatoid arthritis (RA). ${ }^{3-5}$

Objectives: To verify how ultrasound (US) could impact rheumatoid arthritis (RA) treatment decision in real life when fibromyalgia (FM) was also present.

Methods: A retrospective cohort study was performed from 2011 through 2016 , including RA patients with FM. Patients were grouped according to US examination (Group DAS28: never performed US examination; Group US: at least one US exam). RA was considered active if DAS28 $\geq 3.2$ in Group DAS28 or PD $\geq 2$ in any single joint in Group US.

Results: Out of 230 RA patients, 22 women with concomitant FM (Group DAS28 $=10$ and Group US=12) were seen in 280 visits from 2011 through 2016 . DAS28 was $4.4(2.5-6.3)$ vs. $4.0(2.0-5.0)(\mathrm{p}=0,592)$ in Groups DAS28 and US, respectively.

DMARD treatment was escalated in $12.9 \%$ of visits in Group DAS28 versus $8.2 \%$ in Group US ( $p=0.791)$ (table 2). The relative risk (RR) for DMARD escalation in Group US compared to Group DAS28 was 1.08 (95\% Cl 0.60-1.95). However, in $74 \%$ of visits in Group US, DMARD was escalated despite a negative US result. In a theoretical scenario where US result oriented treatment decision, DMARD was escalated in $3.6 \%$ of visits in Groups DAS28 and US, respectively (table 1). Also, in this US-based scenario, the RR for DMARD escalation in Group US compared to Group DAS28 was 0.39 (0.19-0.83).

The proportion of visits with US evaluation increased over time, nonetheless the level of agreement between US synovitis (PD $\geq 2$ ) and DMARD escalation 